\title{
Overexpression of minichromosome maintenance 2 predicts poor prognosis in patients with gastric cancer
}

\author{
CHUN YANG $^{1 *}$, YUGANG WEN ${ }^{3 *}$, HAI LI $^{1}$, DONG ZHANG ${ }^{1}$, NINGMEI ZHANG ${ }^{2}$, XINRONG SHI $^{1}$, \\ BO JIANG ${ }^{1}$, XIAOQIANG MA ${ }^{1}$, PING YANG ${ }^{1}$, HUAMEI TANG ${ }^{4}$, ZHIHAI PENG ${ }^{3}$ and YINXUE YANG ${ }^{1}$ \\ Departments of ${ }^{1}$ Anal-Colorectal Surgery and ${ }^{2}$ Pathology, Affiliated Hospital of Ningxia Medical University, \\ Yinchuan 750004; Departments of ${ }^{3}$ General Surgery and ${ }^{4}$ Pathology, Shanghai First People's \\ Hospital, School of Medicine, Shanghai Jiaotong University, Shanghai 200080, P.R. China
}

Received July 25, 2011; Accepted August 29, 2011

DOI: $10.3892 /$ or.2011.1473

\begin{abstract}
We examined the expression of minichromosome maintenance 2 (MCM2) in gastric cancer and adjacent normal tissues and estimated the possible value of MCM2 as a novel prognostic marker. Using real-time PCR, Western blotting and immunohistochemistry, we examined the expression of MCM2 in gastric carcinoma and paired normal gastric mucosa. Statistical analysis of the expression of MCM2 mRNA and protein in gastric cancer and normal tissues was performed to evaluate the relationship between MCM2 expression and clinicopathological characteristics in gastric cancer. The expression of MCM 2 mRNA and protein in gastric carcinomas was significantly higher compared to that in normal gastric mucosa $(\mathrm{P}=0.04)$. Immunohistochemistry analysis showed that MCM2 expression was significantly up-regulated in tumor and metastastic lymph node tissues compared with the corresponding non-cancerous mucosa $(\mathrm{P}<0.05)$. Positive expression of MCM2 was significantly associated with patient age, $\mathrm{T}$ category and the presence of lymph node metastasis $(\mathrm{P}<0.05)$. There were no differences between MCM2 expression and gender, tumor size, tumor location, M category, International Union Against Cancer (UICC) stage, vessel invasion and tumor differentiation. Patients with negative tumor MCM2 expression displayed a better survival time than those with positive MCM2 expression $(\mathrm{P}<0.05)$. Survival analysis showed that positive MCM2 expression $(\mathrm{P}<0.05)$, $\mathrm{T}$ stage $(\mathrm{P}<0.05)$ and $\mathrm{N}$ stage $(\mathrm{P}<0.05)$ were independent prognostic
\end{abstract}

Correspondence to: Dr Yingxue Yang, Department of AnalColorectal Surgery, Affiliated Hospital of Ningxia Medical University, Yinchuan 750004, P.R. China

E-mail: 18995017676@189.cn

Dr Zhihai Peng, Department of General Surgery, Shanghai First People's Hospital, School of Medicine, Shanghai Jiaotong University, Shanghai 200080, P.R. China

E-mail: pengpzh@hotmail.com

*Contributed equally

Key words: minichromosome maintenance 2, gastric cancer, immunohistochemistry, survival analysis, prognosis factors for disease-free survival (DFS) and overall survival (OS). Our data suggest that MCM2 could serve as a novel prognostic biomarker in gastric carcinoma.

\section{Introduction}

Gastric cancer is one of the most common cancers worldwide. Following lung cancer, gastric cancer is the second leading cause of cancer mortality in the world. According to a global estimation, more than 930,000 new cases of gastric carcinomas are diagnosed per year, and a minimum of 700,000 patients die from the disease $(1,2)$. To better define the biological profile of gastric cancers, many investigations have been undertaken during the last few years. The larger goals of gastric tumor research are to improve early diagnosis and prognostic stratification and eventually cure the disease.

A variable number of numerical or structural genetic aberrations have been reported in gastric cancer cells, and chromosomal changes in DNA copy number have also been reported (3). DNA replication occurs only once during each cell cycle in eukaryotes. This tight control is orchestrated by many regulatory molecules, including the origin recognition complex (ORC), Cdt1, Cdt6 and the minichromosome maintenance (MCM) protein complex (4). The MCM complex appears to play a key role in DNA replication, acting as a replication initiation factor. Minichromosome maintenance proteins (MCMs) are a family of closely related proteins with striking sequence homology. The MCM protein family consists of six major isoforms (2-7), having similar biochemical functions (5) and being required for the initiation and elongation of DNA replication (6). MCM2 through MCM7 are the components of a ring-shaped heterohexameric MCM complex, designated as the pre-replication complex (pre-RC), that is thought to act as a replicative helicase at the replication fork (7). Cdc6 and Cdt1 recruit the MCM complex to the ORC, licensing the DNA for replication, and then dissociate irreversibly, preventing replication from occurring more than once during each cell cycle (8). Moreover, the MCM complex is present only in proliferating cells and is absent in quiescent cells (9-11). Due to the vital role of this complex in genome duplication in proliferating cells, deregulation of MCM function results in chromosomal defects that may contribute to tumorigenesis. Therefore, the strict 
relation of the MCM protein family to chromatin replication allows MCM to be used as a specific proliferation marker (12). MCM2 is a member of the MCM protein family, that plays an important role in two crucial steps of the cell cycle, namely, the onset of DNA replication and cell division (13). Recently, the MCM2 protein has been proposed to be a candidate marker for cancer screening, surveillance and prognosis (14-18), but the clinical significance and prognostic value of MCM2 expression in gastric cancer have not been reported.

PCNA (proliferation cell nuclear antigen) has been found to be one of the most reliable markers of cell proliferation. PCNA is a nuclear protein that interacts with many proteins involved in DNA replication and repair, thus protecting the DNA sequence pattern (6). The concentration of PCNA correlates with cell proliferation (19). The relationship between MCM2 and PCNA in gastric cancer has not yet been investigated.

In this study, we used real-time reverse transcription-PCR, Western blot analysis and immunohistochemistry to examine the expression of MCM2 in gastric carcinoma, adjacent normal gastric mucosa and archived specimens of lymph node metastasis to investigate the correlation of MCM2 expression with the clinicopathological features of gastric cancer and to evaluate whether MCM2 could be used as a predictive biomarker in patients with gastric cancer.

\section{Materials and methods}

Tissue samples. The study group consisted of 264 patients with confirmed gastric cancer who underwent curative gastrectomy by the same surgical team at the General Surgery Department of Shanghai Jiao Tong University Affiliated First People's Hospital between November 2003 and May 2009. The diagnoses were confirmed by at least two pathologists, and staging was determined based upon pathological findings, according to the International Union Against Cancer (UICC) guidelines. None of the patients had received preoperative chemotherapy and/or radiation therapy. The group included 157 males and 107 females with a mean age of 66 years (range 27-89 years). One hundred and four specimens of gastric cancer paired with normal mucosa and lymph node metastases were available in our archive. The follow-up period for survivors was 2-68.5 months after surgery, and the final date was September, 15 2009. All of the patients provided informed consent as outline in the protocol approved by the institutional review board of the Shanghai Jiao Tong University Affiliated First People's Hospital.

RNA extraction, $c D N A$ preparation and quantitative real-time $P C R$. Total RNA was isolated from 45 randomly selected specimens of frozen gastric tumor tissues and the corresponding normal tissues (at a distance of $2 \mathrm{~cm}$ from the tumor) according to the manufacturer's instructions (Qiagen Gmbh, Hilden, Germany). The quality of the RNA was examined by electrophoresis in agarose gels stained with ethidium bromide, and the $18 \mathrm{~S}$ and 28S RNA bands were visualized under UV light. One microgram of RNA was reverse transcribed into complementary DNA using an A3500 RT-PCR system (Promega Corp., Madison, WI, USA). Real-time PCR was performed using an ABI Prism 7500 quantitative real-time PCR (qPCR) system (Applied Biosystems, Foster City, CA, USA) and the $\mathrm{IQ}^{\mathrm{TM}}$
SYBR Green Supermix kit (Bio-Rad) according to the manufacturer's instructions. The primers for qPCR were: MCM2, sense 5'-CTACCAGCGTATCCGAATCCA-3' and antisense 5'-GGGAGCCATCATAGTTGTTGTG-3'; glyceraldehyde 3-phosphate dehydrogenase (GAPDH), sense 5'-AAGGTCAT CCCTGAGCTGAA-3' and antisense 5'-TGACAAAGTGGTC GTTGAGG-3'. The cycling conditions were as follows: initial denaturation $\left(10 \mathrm{~min}\right.$ at $\left.95^{\circ} \mathrm{C}\right)$, followed by 42 cycles of denaturation $\left(10 \mathrm{sec}\right.$ at $\left.95^{\circ} \mathrm{C}\right)$, annealing $\left(20 \mathrm{sec}\right.$ at $\left.60^{\circ} \mathrm{C}\right)$, and elongation $\left(1 \mathrm{~min}\right.$ at $\left.72^{\circ} \mathrm{C}\right)$. All PCR reactions were performed in triplicate. The mean MCM2 level for each tumor was compared to the level in the corresponding normal tissue. The fold change $\left(2^{-\Delta \Delta C t}\right)$ in MCM2 expression in each paired sample was calculated using the following formulas: $\mathrm{MCM} 2^{\Delta \mathrm{Ct}}=(\mathrm{Avg}$. $\left.\mathrm{Ct}_{\mathrm{MCM} 2}-\mathrm{Avg} . \mathrm{Ct}_{\mathrm{GAPDH}}\right)$ and $\mathrm{MCM} 2^{\Delta \Delta \mathrm{Ct}}=\left(\mathrm{MCM}^{\Delta \mathrm{Ct}}{ }_{\text {tumor }}-\right.$ $\left.\mathrm{MCM}^{\Delta \mathrm{Ct}}{ }_{\text {normal }}\right)$.

Western blot analysis. Protein was extracted from freshfrozen gastric cancer tissue and the corresponding normal tissue using the Whole Protein Extraction kit (Fermentas, USA). Aliquots of proteins were electrophoresed using $10 \%$ SDS-PAGE and were transferred onto polyvinylidene difluoride (PVDF) membranes. The PVDF membranes were blocked with $5 \%$ non-fat milk solution for $2 \mathrm{~h}$ at room temperature and then incubated with the MCM2 primary rabbit monoclonal antibody (1:1000, Cell Signaling Technology, USA) at $4^{\circ} \mathrm{C}$ overnight. After washing with TBST buffer, the membranes were incubated with a goat-anti-rabbit IgG horseradish peroxidase conjugate secondary antibody (1:2000, Cell Signaling Technology) for $45 \mathrm{~min}$ at room temperature. The proteins were detected using enhanced chemiluminescence (Pierce Biotechnology, Rockford, IL, USA) and exposure to X-ray film. Each protein was assayed and normalized against $\beta$-actin (Cell Signaling Technology) expression.

TMA construction. Hematoxylin and eosin (H\&E)-stained slides were retrieved from 264 samples of gastric cancer tissues and paired normal mucosa, including 104 samples of paired metastatic lymph nodes. Representative areas were used as a template to construct tissue microarray (TMA) blocks, and 2.0-mm diameter cores were punched from the paraffin blocks in our archive (in collaboration with Shanghai Biochip, Shanghai, China). All of the cases included two cores of cancer tissue and normal tissue on the tissue microarray. The cores were validated as having high accordance with that of the whole archived section.

Immunohistochemistry. Immunohistochemistry was performed using a standard methodology. Briefly, tissue sections were heated in citrate buffer ( $\mathrm{pH}$ 6.0) in a pressure cooker for 6 min and incubated with an anti-MCM2 antibody (1:400 Cell Signaling Technology) and an antibody against the proliferation marker PCNA (1:50 Dako Cytomation) overnight at $4^{\circ} \mathrm{C}$. The sections were then incubated with goat anti-mouse or anti-rabbit Envision System plus-HRP (Dako Cytomation) for $30 \mathrm{~min}$ at room temperature and were counterstained with Mayer's hematoxylin.

The reactions for MCM2 protein and PCNA were observed in the cell nucleus. Protein expression was evaluated on the basis of the intensity and extent of staining. Staining intensity 


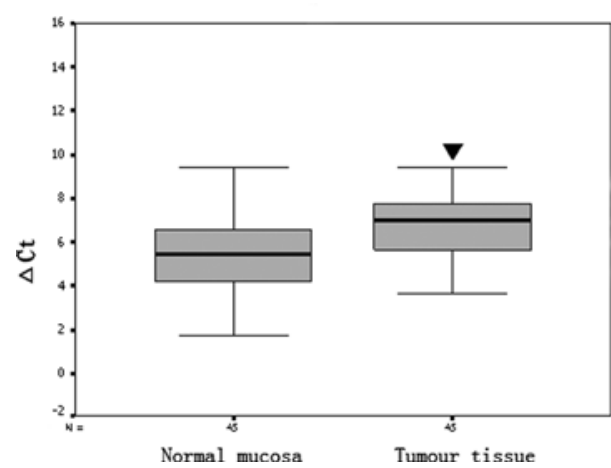

Figure 1. Real-time PCR analysis of MCM2 mRNA expression in 45 paired gastric carcinoma samples and in the adjacent normal mucosa. For each sample, the relative MCM2 mRNA level was normalized using GAPDH expression. Data are presented as the median $\Delta \mathrm{Ct}$ value with boxed 25 th and 75th percentiles. ${ }^{\top} \mathrm{P}<0.001$

was graded as: 0 , no staining; 1 , weak staining; and 2, strong staining. The staining extent was scored as: $0,0-25 \%$ of the cell nucleus stained positive; $1,26-50 \%$ stained positive; 2 , $51-75 \%$ stained positive; or $3,75-100 \%$ stained positive. The sum of the intensity and extent scores was designated as $0-2$, negative expression and 3-5, positive expression. All TMA slides were examined independently by two histopathologists who were blinded to patient outcome, and an agreement was obtained.

Statistical analysis. Statistical analyses were performed using the SPSS 13.0 software package (SPSS Inc., Chicago, IL, USA). The significance of differences between means was determined by a bivariate analysis with a paired t-test or the Wilcoxon signed rank test. The $\chi^{2}$ test was used for comparisons between MCM2 and PCNA expression and clinicopatholigical variables. Survival rates were estimated by the Kaplan-Meier method, and the differences between the survival curves were assessed by the log-rank test. Univariate and multivariate Cox regression models for survival were used to evaluate the contributions of factors. Differences between groups were considered significant when $\mathrm{P}<0.05$.

\section{Results}

Comparison of MCM2 expression between gastric cancer and adjacent normal mucosa. The expression levels of MCM2

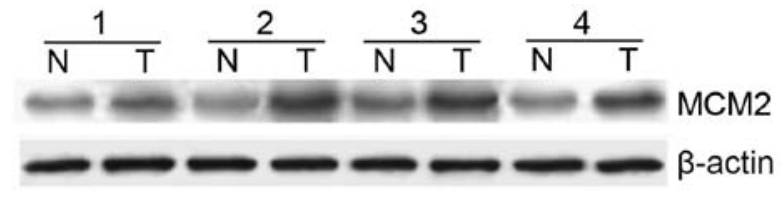

Figure 2. Western blot analysis of MCM2 expression in gastric carcinoma (T) and paired adjacent normal tissues $(\mathrm{N}) . \beta$-actin is the loading control.

mRNA were examined in 45 randomly selected, paired cases by real-time PCR. The results indicated that $27(60 \%)$ gastric cancer tissues showed at least a 2-fold increase in MCM2 mRNA levels compared to the adjacent normal mucosa $(\mathrm{P}<0.001$, Fig. 1). Subsequent Western blotting confirmed that the expression of MCM2 protein was significantly up-regulated in gastric cancer tissues compared to the corresponding non-cancerous mucosa (Fig. 2).

Immunohistochemical findings. To confirm the expression levels of MCM2 shown by Western blot analysis, immunohistochemistry was performed on TMA consisting of 264 patients. As shown in Fig. 3, MCM2 and PCNA positive staining was observed primarily in the nuclei of cancer cells. Among the specimens of normal mucosa on the paired TMA, 54 (20.45\%) showed positive staining, and 210 (79.55\%) showed negative MCM2 expression. In contrast, among the 264 specimens of gastric cancer tissue, 181 (68.56\%) showed positive staining, and negative staining was observed in $83(31.44 \%)$ cases. MCM2 expression was significantly up-regulated in tumor tissues compared to the corresponding non-cancerous mucosa $(\mathrm{P}<0.05)$. In addition, MCM2 expression in matched gastric cancer and lymph node metastatic tissues were evaluated. Of the 104 cases of lymph node metastases analyzed, 85 samples $(81.73 \%)$ showed MCM2 overexpression, which was higher than that in the paired primary cancer tissues (Table I, $\mathrm{P}<0.05)$, indicating that up-regulated MCM2 expression might correlate with gastric cancer metastasis.

Correlation of MCM2 and PCNA expression with clinicopathological characteristics in gastric cancer. We evaluated the correlation between the positive expression of MCM2 and PCNA and the clinicopathological profiles (Table II). Positive expression of MCM2 was significantly associated with patient age, $\mathrm{T}$ category and lymph node metastasis $(\mathrm{P}<0.05)$. Factors

Table I. Expression of MCM2 in normal gastric mucosa, cancerous tissues and lymph node metastasis tissues.

Expression of MCM

\begin{tabular}{lcrrr} 
Tissue sample & $\mathrm{n}$ & Negative $(\%)$ & Positive $(\%)$ & P-value $\left(\chi^{2}\right.$ test $)$ \\
\hline Normal mucosa & 264 & $210(79.55)$ & $54(20.45)$ & $<0.001^{\mathrm{a}}$ \\
Gastric cancer tissues & 264 & $83(31.44)$ & $181(68.56)$ & $<0.01^{\mathrm{b}}$ \\
Lymph node metastasis tissues & 104 & $19(18.27)$ & $85(81.73)$ & $<0.001^{\mathrm{c}}$ \\
\hline
\end{tabular}

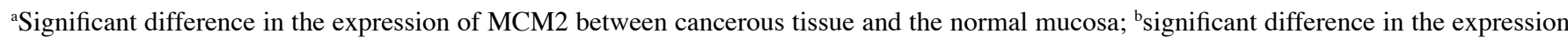
of MCM2 between cancerous tissue and the lymph node metastasis (LNM) tissue sample; ${ }^{c}$ significant difference in the expression of MCM2 between the LNM tissue sample and the normal mucosa tissue sample. 

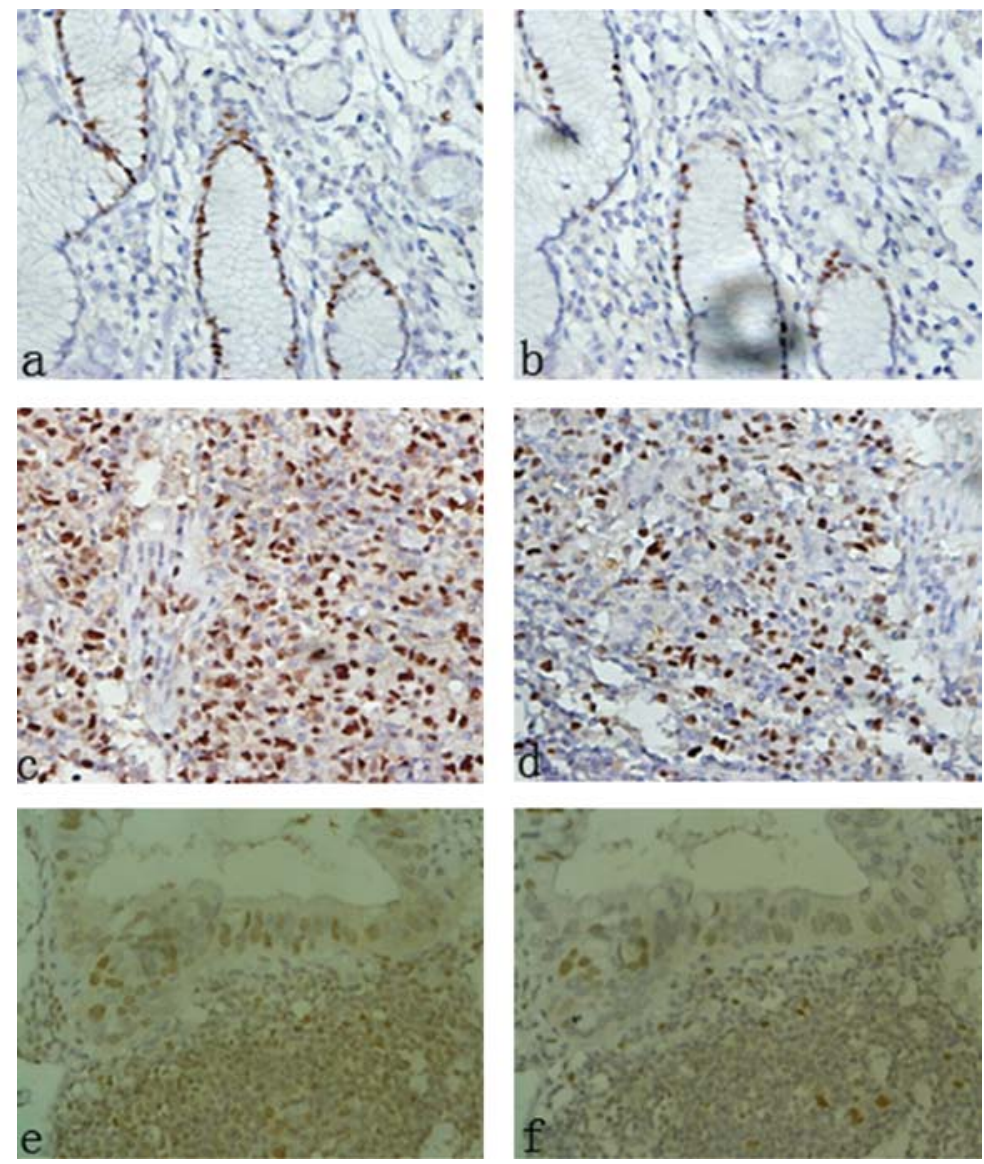

Figure 3. Analysis of MCM2 and PCNA protein expression by immunohistochemistry in gastric cancer, normal mucosa, and LNM specimens. MCM2 and PCNA expression was localized within the nuclei. MCM2 (a) and PCNA (b) expression in normal mucosa. Strong immunostaining of MCM2 (c) and coexpression of PCNA (d) in gastric cancer is noted. MCM2 (e) and PCNA (f) overexpressed in LNM (original magnification, x200).

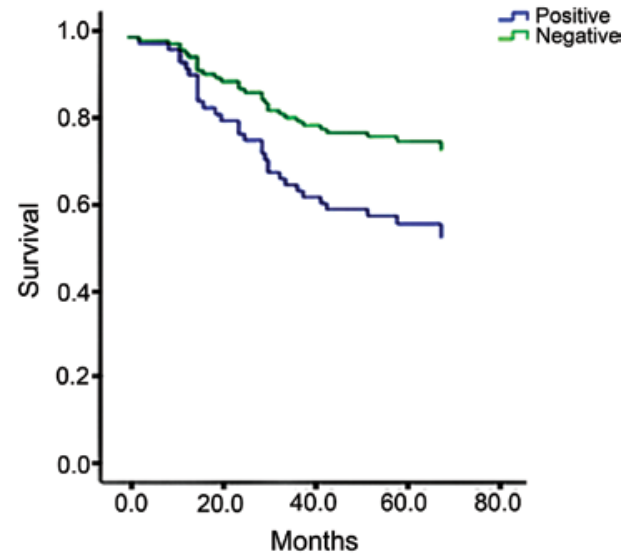

Figure 4. Correlation of MCM2 expression in the primary tumor mass with the survival of patients with gastric cancer.

that were not significantly associated with MCM2 expression included patient gender, tumor size, location of the tumor, $\mathrm{M}$ category, UICC stage, vessel invasion and the extent of tumor differentiation.

The paired gastric tumor and normal mucosa TMA was also stained for PCNA expression. Positive staining was observed in $162(61.36 \%)$ cases. PCNA overexpression was significantly associated with patient age, $\mathrm{T}$ category and LN metastasis $(\mathrm{P}<0.05)$. Moreover, we found that positive immunostaining for MCM2 was more frequently detected in specimens that also showed overexpression of PCNA $(\mathrm{P}=0.028)$. The co-expression of MCM2 and PCNA was often observed in the same area of the tumor tissues (Fig. 3).

Survival analysis. Survival analysis indicated that the patients with negative tumor MCM2 expression had a better survival time than those with positive MCM2 expression (50 months vs. 31 months, $\mathrm{P}<0.05$ ). The survival time of patients with negative PCNA expression in gastric cancer was longer than those with positive PCNA expression (47 months vs. 26 months, $\mathrm{P}<0.05$ ). Kaplan-Meier curves showed that the rate of recurrence was significantly elevated in tumors with positive MCM2 expression (Fig. 4).

The 5-year OS rate of 264 patients with gastric cancer was $63 \%$, with 98 deaths observed during the follow-up period. The 5 -year DFS rate was 56\%, with 112 events observed during follow-up.

By univariate analysis (Table III), PCNA ( $\mathrm{P}<0.05)$, patient age $(\mathrm{P}<0.05)$, the $\mathrm{T}$ stage $(\mathrm{P}<0.01)$, the $\mathrm{N}$ stage $(\mathrm{P}<0.01)$, the $\mathrm{M}$ stage $(\mathrm{P}<0.01)$, the UICC stage $(\mathrm{P}<0.01)$ and the extent of vessel invasion $(\mathrm{P}<0.01)$ were associated with OS and DFS. Multivariate analysis demonstrated that positive carcinoma MCM2 expression $(\mathrm{P}<0.05)$, the $\mathrm{T}$ stage $(\mathrm{P}<0.05)$ and the $\mathrm{N}$ stage $(\mathrm{P}<0.05)$ were independent prognostic factors for DFS and OS. 
Table II. Correlation between MCM2 and PCNA expression determined by immunohistochemical staining and clinicopathological features in patients with gastric cancer $(n=264)$.

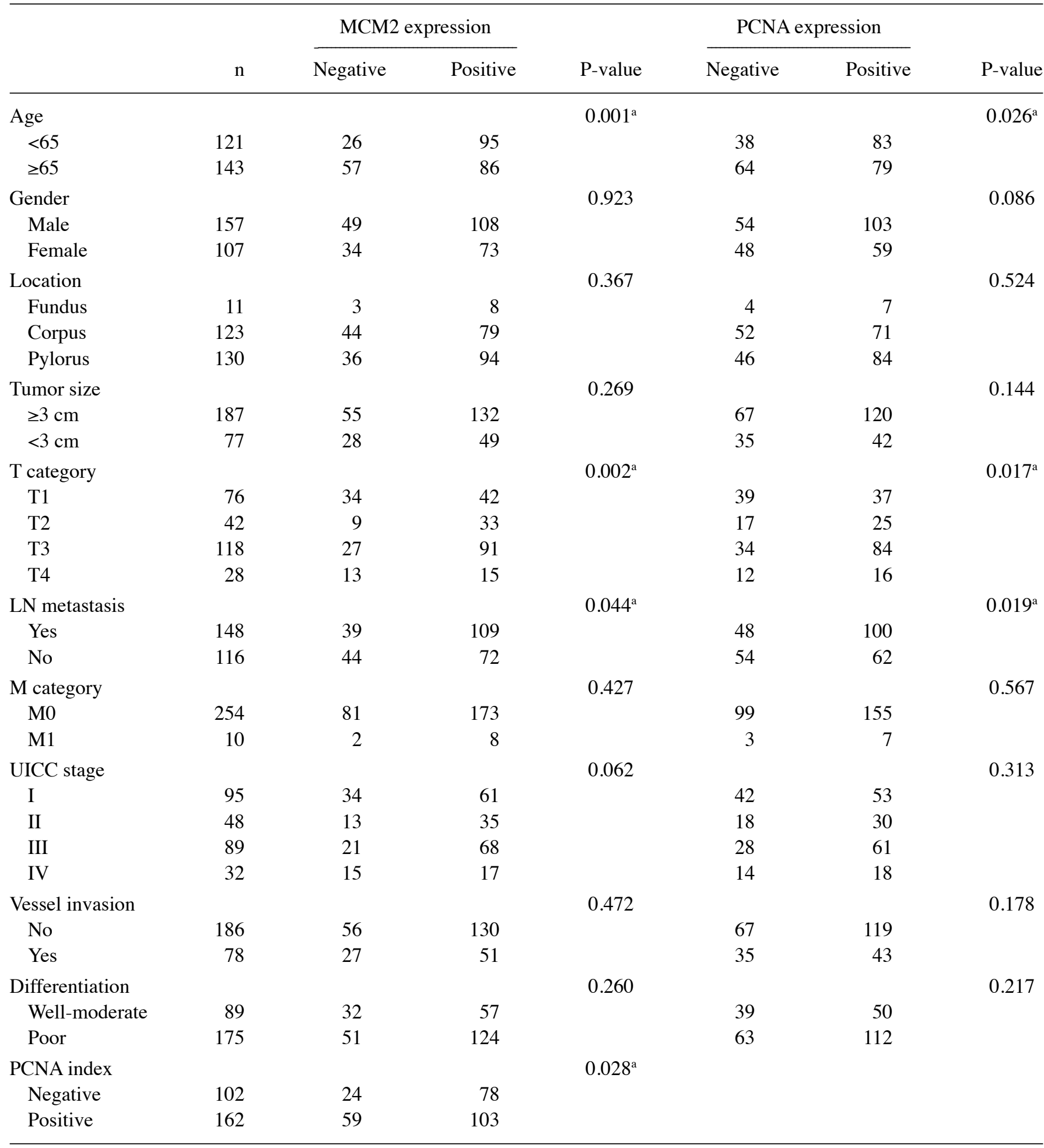

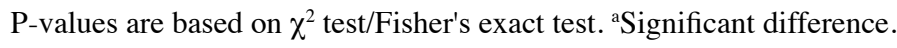

\section{Discussion}

MCM2 is one of six members of the minichromosome maintenance family of proteins (MCMs). MCMs make up a family of closely related proteins with striking sequence homology that was first discovered in yeast. Similar classes have been found in Xenopus, murine, and human cells, with significant conservation of gene sequences $(10,20)$. Expression of minichromosome maintenance proteins is a prerequisite for DNA replication and cell-cycle initiation (10). Specifically, MCM2 serves as a 'licensing factor' and is essential for the initiation of DNA replication. The dissociation of MCM2 irreversibly 


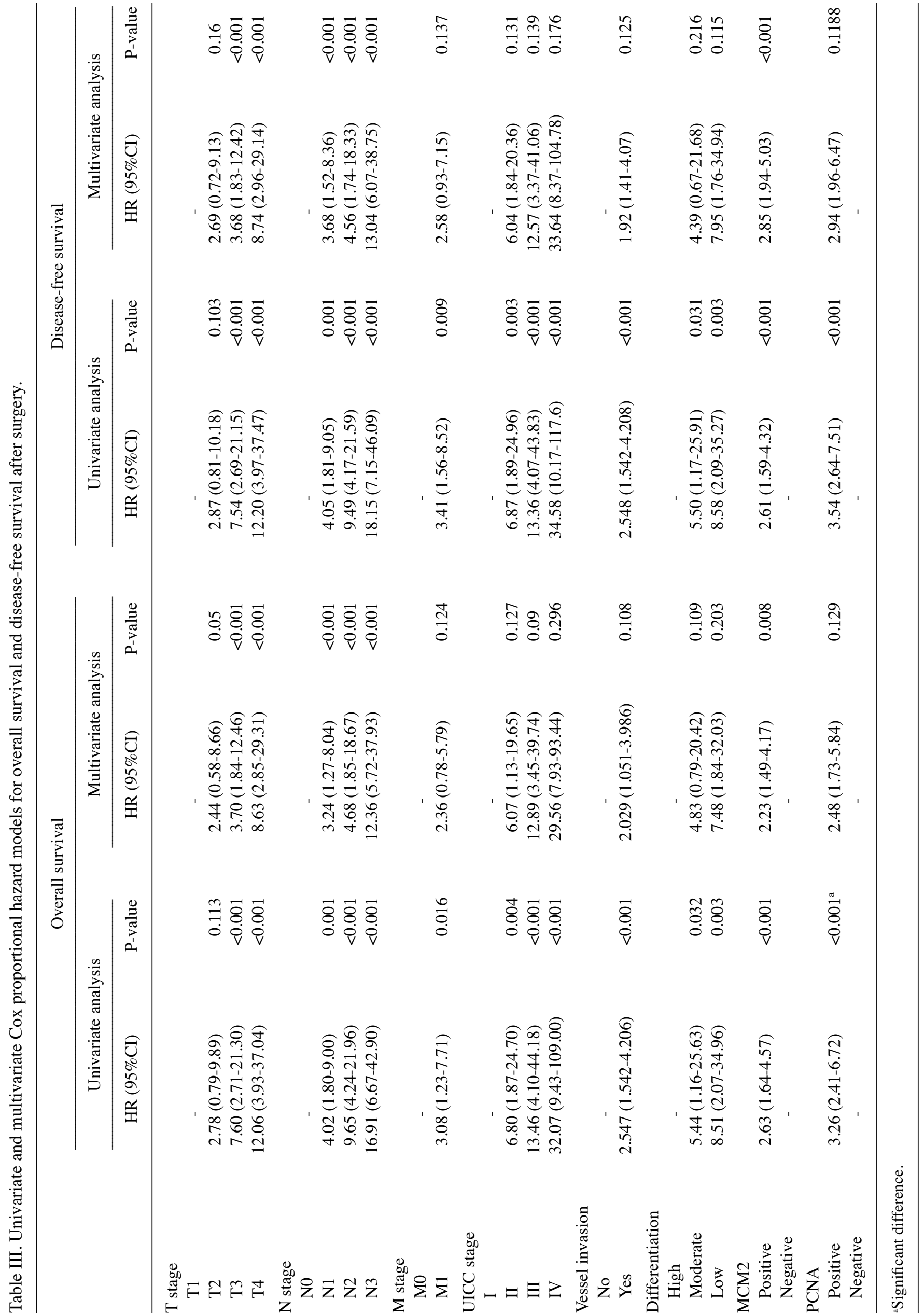


limits replication to one round during each cell cycle $(9,11)$. The MCM2 protein is absent in quiescent and senescent cells, but is present in proliferating cells. These functions of MCM2 imply that the expression of this protein correlates with cell proliferation. For the past few years, MCM2 has been proposed as a candidate marker for cancer screening, surveillance and prognosis $(14,15)$. Wang et al (21) have evaluated the expression of MCM2 mRNA in colorectal normal mucosa, adenoma, and adenocarcinoma. They determined that the expression of MCM2 mRNA in adenocarcinomas is significantly higher than in adenomas. This result suggested the potential value of MCM2 in the early diagnosis of colorectal cancer. In addition, MCM2 protein expression could predict the survival of patients with oral or esophageal squamous cell carcinoma $(16,22)$, non-small cell lung cancer (18), brain tumors (23), prostate cancer (24), breast cancer (17) and renal cell cancer (14). In this study, we measured MCM2 expression by realtime PCR and Western blot analysis in fresh-frozen specimens of gastric cancer and found that MCM2 mRNA and protein expression levels were higher in gastric cancer tissue than in the surrounding non-cancerous mucosa.

These results indicate that MCM2 was up-regulated at both the transcriptional and post-transcriptional levels and that MCM2 may be a novel molecular marker for gastric cancer. Further validation by immunohistochemistry showed that $68.56 \%(181 / 264)$ of the gastric cancer samples contained positive staining for the MCM2 protein, whereas only $20.45 \%$ (54/264) of the normal gastric epithelium samples contained positive MCM2 protein staining. The data suggest that MCM2 may have an important role in the evolution of malignancies from their precursor lesions and that it may be possible to use MCM2 as a novel diagnostic marker. We also examined the expression of MCM2 in lymph node metastases and found greater positive MCM2 protein staining than in the gastric cancer specimens. This elevation in expression suggests that MCM2 might play a critical role in the development of metastases.

MCM proteins have been reported to correlate with the TNM classification or histological grade in other cancers, including prostate cancer, renal cell carcinoma and lung adenocarcinoma $(18,25,26)$. Czyzewska et al (27) assessed the proliferation indices (PI) of Ki-67, PCNA and MCM2 proteins in advanced gastric cancer and in metastatic lymph nodes and the correlation of these markers with certain clinicopathological features; they concluded that Ki-67, PCNA and MCM2 PI in tumor tissue and metastatic lymph nodes were significantly correlated with the depth of wall invasion and local lymph node involvement. In our study, we revealed a significant correlation between elevated MCM2 expression and patient age $(\mathrm{P}=0.026)$, $\mathrm{T}$ category $(\mathrm{P}=0.002)$ and the presence of lymph node metastasis $(\mathrm{P}=0.044)$. These strong correlations suggest that MCM2 overexpression may promote tumor invasion and metastasis. Therefore, MCM2 could be used as a biomarker to identify subsets of gastric cancer with a more aggressive phenotype. We also showed a significant association between MCM2 and the cell proliferation marker PCNA $(\mathrm{P}=0.028)$, suggesting that MCM2 may be involved in the increased proliferation of gastric cancer cells. Our study revealed that MCM2 positive expression was higher in tumors with associated lymph node metastasis than in those without lymph node metastases. The positive expression of MCM2 was significantly higher in metastatic gastric cancer cells within lymph nodes than in matched tumors. These data suggest that positive expression of MCM2 may correlate with the invasive and metastatic processes of gastric cancer. Mita et al (28) have revealed a strong correlation between the proliferative activity of tumor cells and the presence of metastases to lymph nodes and prognosis in cancers. They have demonstrated that tumors with high proliferative activity have high lymph node metastatic potential. In our study, we found that patients with high tumor MCM2 expression had a higher risk of tumor infiltrates and metastases and a shorter survival. Our data are consistent with those published by Kato et al (16), who have observed that high MCM2 PI in alimentary tract carcinomas indicates a more unfavorable prognosis and greater biological aggressiveness of the tumor. Other data in the literature concerning MCM2 PI in alimentary tract carcinomas have suggested that this marker is more sensitive and better for the assessment of the growth fraction than Ki-67 or PCNA (16).

In conclusion, our results suggest that MCM2 overexpression may be associated with a highly aggressive phenotype of gastric cancer and that MCM2 could serve as a prognostic biomarker for this disease. Further studies are needed to clarify the role of MCM2 in the progression of gastric cancer.

\section{Acknowledgements}

This study was partly supported by the National Natural Science Foundation of China (30960370) and the Medical Guidance Research Project of the Science and Technology Commission of Shanghai Municipality (10411967300).

\section{References}

1. Parkin DM, Bray F, Ferlay J and Pisani P: Global cancer statistics, 2002. CA Cancer J Clin 55: 74-108, 2005.

2. Malekzadeh R, Derakhshan MH and Malekzadeh Z: Gastric cancer in Iran: epidemiology and risk factors. Arch Iran Med 12: 576-583, 2009.

3. El-Rifai W and Powell SM: Molecular biology of gastric cancer. Semin Radiat Oncol 12: 128-140, 2002.

4. Nishitani $\mathrm{H}$ and Lygerou Z: Control of DNA replication licensing in a cell cycle. Genes Cells 7: 523-534, 2002.

5. Tye BK: MCM proteins in DNA replication. Annu Rev Biochem 68: 649-686, 1999

6. Labib K, Tercero JA and Diffley JF: Uninterrupted MCM2-7 function required for DNA replication fork progression. Science 288: 1643-1647, 2000.

7. Pacek M, Tutter AV, Kubota Y, Takisawa $\mathrm{H}$ and Walter JC: Localization of MCM2-7, Cdc45, and GINS to the site of DNA unwinding during eukaryotic DNA replication. Mol Cell 21: 581-587, 2006.

8. Romanowski P and Madine MA: Mechanisms restricting DNA replication to once per cell cycle: the role of Cdc6p and ORC. Trends Cell Biol 7: 9-10, 1997.

9. Tan DF, Huberman JA, Hyland A, et al: MCM2 - a promising marker for premalignant lesions of the lung: a cohort study. BMC Cancer 1: 6, 2001.

10. Kearsey SE and Labib K: MCM proteins: evolution, properties, and role in DNA replication. Biochim Biophys Acta 1398: 113-136, 1998.

11. Todorov IT, Werness BA, Wang HQ, et al: HsMCM2/BM28: a novel proliferation marker for human tumors and normal tissues. Lab Invest 78: 73-78, 1998.

12. Maiorano D, Lutzmann M and Mechali M: MCM proteins and DNA replication. Curr Opin Cell Biol 18: 130-136, 2006.

13. Mincheva A, Todorov I, Werner D, Fink TM and Lichter P: The human gene for nuclear protein BM28 (CDCL1), a new member of the early S-phase family of proteins, maps to chromosome band 3q21. Cytogenet Cell Genet 65: 276-277, 1994. 
14. Rodins K, Cheale M, Coleman N and Fox SB: Minichromosome maintenance protein 2 expression in normal kidney and renal cell carcinomas: relationship to tumor dormancy and potential clinical utility. Clin Cancer Res 8: 1075-1081, 2002.

15. Hunt DP, Freeman A, Morris LS, et al: Early recurrence of benign meningioma correlates with expression of mini-chromosome maintenance-2 protein. Br J Neurosurg 16: 10-15, 2002.

16. Kato H, Miyazaki T, Fukai Y, et al: A new proliferation marker, minichromosome maintenance protein 2 , is associated with tumor aggressiveness in esophageal squamous cell carcinoma. J Surg Oncol 84: 24-30, 2003.

17. Gonzalez MA, Pinder SE, Callagy G, et al: Minichromosome maintenance protein 2 is a strong independent prognostic marker in breast cancer. J Clin Oncol 21: 4306-4313, 2003.

18. Hashimoto K, Araki K, Osaki M, Nakamura H, Tomita K, Shimizu E and Ito H: MCM2 and Ki-67 expression in human lung adenocarcinoma: prognostic implications. Pathobiology 71: 193-200, 2004.

19. Skotnicka-Klonowicz G, Kobos J, Los E, Trejster E, SzymikKantorowicz S and Daszkiewicz P: Prognostic value of proliferating cell nuclear antigen in Wilms' tumour in children. Eur J Surg Oncol 28: 67-71, 2002.

20. Dutta A and Bell SP: Initiation of DNA replication in eukaryotic cells. Annu Rev Cell Dev Biol 13: 293-332, 1997.

21. Wang Y, Li Y, Zhang WY, et al: mRNA expression of minichromosome maintenance 2 in colonic adenoma and adenocarcinoma. Eur J Cancer Prev 18: 40-45, 2009.

22. Kodani I, Shomori K, Osaki M, Kuratate I, Ryoke K and Ito H Expression of minichromosome maintenance 2 (MCM2), Ki-67, and cell-cycle-related molecules, and apoptosis in the normaldysplasia-carcinoma sequence of the oral mucosa. Pathobiology 69: $150-158,2001$
23. Wharton SB, Chan KK, Anderson JR, Stoeber K and Williams GH: Replicative $\mathrm{Mcm} 2$ protein as a novel proliferation marker in oligodendrogliomas and its relationship to Ki67 labelling index, histological grade and prognosis. Neuropathol Appl Neurobiol 27: 305-313, 2001.

24. Meng MV, Grossfeld GD, Williams GH, et al: Minichromosome maintenance protein 2 expression in prostate: characterization and association with outcome after therapy for cancer. Clin Cancer Res 7: 2712-2718, 2001.

25. Dudderidge TJ, Stoeber K, Loddo M, Atkinson G, Fanshawe T, Griffiths DF and Williams GH: Mcm2, Geminin, and Ki67 define proliferative state and are prognostic markers in renal cell carcinoma. Clin Cancer Res 11: 2510-2517, 2005.

26. Padmanabhan V, Callas P, Philips G, Trainer TD and Beatty BG: DNA replication regulation protein $\mathrm{Mcm} 7$ as a marker of proliferation in prostate cancer. J Clin Pathol 57: 1057-1062, 2004.

27. Czyzewska J, Guzinska-Ustymowicz K, Pryczynicz A, Kemona A and Bandurski R: Immunohistochemical evaluation of Ki-67, PCNA and MCM2 proteins proliferation index (PI) in advanced gastric cancer. Folia Histochem Cytobiol 47: 289-296, 2009.

28. Mita T and Shimoda T: Risk factors for lymph node metastasis of submucosal invasive differentiated type gastric carcinoma: clinical significance of histological heterogeneity. J Gastroenterol 36: 661-668, 2001. 